\title{
Recuperando a ênfase na dimensão pública dos estudos organizacionais*
}

\author{
Jean-Claude Thoenig **
}

SUMÁRIO: 1. Introdução; 2. Crescimento e declínio da sociologia organizacional; 3. O que a teoria-padrão clássica deixou inacabado; 4. Aproveitando os estudos sobre formulação de políticas; 5 . Um arcabouço analítico; 6. De organização a organizante e organizado.

SUMMARY: 1 Introduction; 2. Rise and decline of organizational sociology; 3. What the standard classic theory left unachieved; 4. Taking advantage of policymaking studies; 5 . An analytical framework; 6. From organization to organizing and organized.

PalaVras-chave: análise organizacional; dimensão pública; organizada; organizante; administração pública.

KEY WORDS : organizational analysis; publicness; organized; organizing; public administration.

A dimensão pública ainda é tema merecedor de pesquisa? A sociologia organizacional clássica (ou teoria-padrão) abriu o caminho para a compreensão da administração e da gerência públicas, mas não explorou todas as possibilidades colocadas. A dimensão pública caracteriza-se, do ponto de vista analítico, por duas funções de produção: eficiência (produtos) e efetividade (resultados societais). Muito embora possa haver semelhanças entre instituições públicas e não-públicas no tocante a alguns aspectos de

\footnotetext{
* Trabalho originalmente apresentado no encontro Egos-Laemos em Puebla, México, jan. 2006. Tradução de Eoin Paul O'Néill. Artigo recebido e aceito em jun. 2007.

** Diretor emérito de pesquisas no Centre National de la Recherche Scientifique (CNRS), Programa Dauphine de Pesquisa sobre Gerenciamento (DMSP, Université Paris Dauphine). Foi reitor e professor titular do Insead e co-fundador, bem como o primeiro secretário-geral do Egos (European Group for Organization Studies). Sociólogo e cientista político, escreveu vários livros e artigos pioneiros sobre Estado e organizações territoriais, gerenciamento público, análise e avaliação de políticas, bem como sobre o gerenciamento de empresas e sobre mercados. E-mail: jean-claude.thoenig@dauphine.fr.
} 
seus modelos organizacionais, a função de efetividade à qual cada uma delas responde é bastante específica. Tal concepção sugere que os pesquisadores de administração e organização públicas explorem novas perspectivas, tais como organizantes e as organizadas (ou, noutros termos, coloquem uma agenda teórica ampliada).

\section{Rescuing publicness from organizational studies}

Does publicness still make sense as an issue for further research? Classic organizational sociology (or standard theory) has provided a breakthrough for understanding public administration and management, but has not fully explored the agenda. Publicness is analytically characterized by the ownership of two production functions: efficiency (outputs), effectiveness (societal outcomes). While similarities may exist between public and nonpublic entities on some aspects of their organizational models, the effectiveness function they are accountable for is quite specific. Such a perspective allows public administration and organizational scholars to explore new perspectives such as organizing and organized (or the agenda of extended theory).

\section{Introdução}

Ainda vale a pena estudar o setor público e a administração pública através das lentes da teoria e da análise organizacionais modernas? No mundo real continua-se a enfrentar temas e demandas que requerem a intervenção de algum tipo de ação pública e que mecanismos de mercado ou iniciativas filantrópicas seriam incapazes de suprir. Não obstante, a produção de conhecimento sobre organização, organizada e organizante parece bem entorpecida quando se considera a dimensão pública como área de estudo específica.

As perspectivas colocadas pela teoria da agência e pelo neoinstitucionalismo, só para lembrar algumas, exercem grande influência nos estudos sobre administração pública. Comparativamente, a pesquisa inspirada pela sociologia organizacional perdeu parte considerável do peso que tinha na disciplina no final da década de 1960 e na de 1970.

Até mesmo os estudos organizacionais ortodoxos enquanto campo de análise inspiram-se ou baseiam-se muito menos nas organizações públicas do que em outros tipos de objeto, como gerenciamento privado ou regimes econômicos, empresas e mercados. Um olhar sobre as publicações e colóquios sugere que na maioria das vezes se recorre às agências públicas meramente como ilustração empírica na análise de aspectos mais gerais da teoria organizacional. Elas podem também alimentar a produção de conhecimento e as 
abordagens em áreas especializadas ou em domínios restritos, como os referentes a saúde, educação, segurança ou benefícios sociais.

Hoje em dia é bastante baixa a proporção de artigos apresentados em conferências internacionais sobre análise organizacional que lidam especificamente com organizações e administração do setor público. Declinou, só para dar um exemplo, de $42 \%$ para 7\% quando se comparam quatro colóquios Egos ocorridos na década de 1980 com os quatro ocorridos entre 1999 e 2002. ${ }^{1}$ Também são menos numerosas as teses de doutorado que lidam com estruturas públicas em geral e administração pública em particular. Num país como a França, no qual as contribuições da sociologia organizacional foram muito influentes entre o fim da década de 1960 e a década de 1980, o número total de teses caiu para menos da metade desde a década de 1990, enquanto as análises organizacionais sobre empresas e organizações sem fins lucrativos mais do que triplicaram, segundo o Ministério da Educação Superior. Até mesmo revistas especializadas da Europa, bem como dos Estados Unidos, evidenciam um declínio significativo do interesse pelo tema. Vários fatores podem explicar tal falta de entusiasmo e criatividade acadêmicos.

O retorno de valor agregado da produção de conhecimento sobre organizações públicas estaria estacionário, senão declinante. As análises tenderiam a repisar velhos temas, tais como o paradigma burocrático.

Ciclos e modismos também têm sua parcela de culpa. Redigir contribuições dentro das escolas de pensamento supostamente dominantes ou em voga, como teoria de redes, linhas de dependência ou estudos críticos, tornaria muito mais fácil o acesso à carreira e aos periódicos acadêmicos.

Instituições de educação profissionalizante, como escolas de negócios, oferecem mais e melhores oportunidades de emprego do que os departamentos acadêmicos de sociologia, administração pública e ciência política. Isto coincide com uma época em que as chamadas humanidades enfrentam uma crise de identidade persistente (Horowitz, 1993). À exceção dos assuntos relacionados à nova administração pública gerencial, os recursos para pesquisa também foram drasticamente reduzidos em muitos países, ao menos quando comparados com os disponibilizados para outras áreas.

Outra dimensão relaciona-se à falta de conhecimento demonstrada pelos pesquisadores mais jovens, bem como por alguns de seus professores, no que toca a aspectos básicos das ciências sociais. Produção científica e trabalhos publicados antes da década de 1980 são simplesmente ignorados, o que

\footnotetext{
${ }^{1}$ Fonte: arquivos pessoais.
} 
camufla o progresso acumulado. Alunos de doutorado, quando não seus professores, por vezes evidenciam graves deficiências ou enviesamentos no que lhes foi apresentado nos cursos de graduação a respeito de pontos centrais de disciplinas como sociologia e ciência política.

O objetivo deste artigo é defender que a dimensão pública ainda é tema relevante de pesquisa. Na próxima seção questionamos em que medida os fundamentos do conhecimento organizacional de fato exploraram exaustivamente a dimensão pública. Por exemplo, a sociologia organizacional clássica definida por uma teoria-padrão ou determinação de seu domínio (Thoenig, 1998) - foi responsável por avanços enquanto perspectiva de Verstehen, enquanto estrutura de referência conceitual e metodológica. Contudo, não se voltou de forma decidida nem explorou integralmente uma agenda sobre as organizações públicas em si.

Considerar a dimensão pública como tema é algo que pode beneficiar-se da perspectiva que sugere que as organizações públicas são organizações de uma natureza específica porque, diferentemente de empresas, igrejas ou associações voluntárias, estão encarregadas da efetividade das políticas, de uma função de produção que gera impactos societais. Embora possa haver semelhanças entre entidades públicas e não-públicas no tocante a alguns aspectos de seus modelos organizacionais, a função de produção efetividade à qual entidades públicas e outros órgãos governamentais respondem é muito específica, tanto da perspectiva da ação quanto da do mandato. Essa agenda de pesquisa inspirase em estudos de políticas e sugere a constituição de uma teoria específica das entidades governamentais, que forneça um ângulo, ou arcabouço proveitoso para avaliar a dimensão pública. Analisar políticas ao mesmo tempo como processos e como conteúdos é uma maneira produtiva de acessar ou de penetrar analiticamente na pesquisa sobre organizações públicas. As lacunas no conhecimento que permanecem devem interessar a cientistas políticos, a administradores públicos e a pesquisadores de outras disciplinas afins das ciências sociais.

\section{Crescimento e declínio da sociologia organizacional}

Definir a dimensão pública pelo estatuto formal da organização permanece um critério questionável e vago. Nas sociedades modernas os assuntos públicos estão albergados em uma enorme variedade de estatutos legais e alcances territoriais. Governos em vários níveis, de pequenas comunidades urbanas às Nações Unidas, baseiam-se em conjuntos complexos e altamente diferenciados de organizações formais que controlam (Thoenig, 1997). Não parece fácil traçar uma linha que estabeleça a separação entre público e privado. 
Há outra razão pela qual o recurso ao estatuto formal não constitui uma base sólida. O serviço público na tradição da common law, bem como a administração pública na perspectiva do direito romano não detêm o controle monopolístico do manejo dos assuntos públicos, desde a lei e a ordem, a proteção contra incêndios e as políticas ambientais até a educação, os usos da terra e os benefícios sociais. Desenhos institucionais híbridos e estatutos legais vagos são prática comum. Algumas agências públicas operam em termos próximos aos de mercado e por vezes até competem abertamente com empresas privadas. $\mathrm{O}$ Estado atua como proprietário orientado para o lucro. Em vários setores, como nos ligados a benefícios sociais, as autoridades governamentais subcontratam mandatos de bens coletivos e alocam fundos públicos em organizações sem fins lucrativos, estas últimas obtendo a maioria de seus recursos do dinheiro de impostos, e não de associações filantrópicas ou de clientesusuários. Algumas entidades não-governamentais, como empresas, associações ou grupos de cidadãos, têm papel importante no fornecimento de bens coletivos, com grande frequiência sem disporem de mandato formal para isso. O Estado está longe de ser senhor e deter o controle exclusivo dos assuntos públicos, desde a definição do que deva ser objeto de ação até o desenho e a implementação das ações em si.

Presumir que o fato de essas entidades estarem submetidas a alguma autoridade de Estado ou de governo é característica suficiente para definir sua singularidade pode levar os pesquisadores a ignorar as contribuições oriundas da sociologia das organizações. Nos últimos 50 anos o estatuto científico do setor público nos estudos organizacionais progrediu de modo notável.

Na década de 1960 desenvolve-se um grande debate. O velho institucionalismo inspirado em abordagens formalístico-legais, como a teoria da administração pública na América do Norte e a science administrative na Europa, entra num declínio aparentemente irreversível. Análises mais rigorosas do funcionamento e dos comportamentos organizacionais assumem a frente da cena. Noções como Estado e administração pública tornam-se analiticamente pobres ou frustrantes. Mascaram ordenamentos locais específicos diferenciados. As fronteiras de ação permanecem flutuantes. A dimensão pública não deve ser considerada ponto pacífico ou um axioma, mas como uma questão a ser pesquisada.

A sociologia das organizações também desafiou as perspectivas de teor marxista. Fenômenos de nível médio como as organizações não devem mais ser encarados apenas como superestruturas. Luta de classes e dinâmica dos interesses investidos não são suficientes para explicar como os ministérios e as agências públicas operam. As organizações devem ser encaradas como ordenamentos específicos e sistemas de ação inseridos localmente. 
O final do século XX coincidiu com uma mudança espetacular, como se a sociologia das organizações tivesse de fato perdido seu ímpeto. Outras teorias assumiram a frente da cena acadêmica. As perspectivas sociológicas foram marginalizadas por outras disciplinas ou paradigmas.

Um exemplo disso pode ser encontrado no gerenciamento público da educação. Nos Estados Unidos no início da década de 1970 o gerenciamento público passou a ser encarado como domínio específico. Os temas organizacionais eram colocados como prioritários para serem pesquisados e tratados. Um autor de destaque, Aaron Wildavsky (1979), cientista político por formação, considerava as contribuições de teóricos organizacionais como Martin Landau (1969) fontes centrais de inspiração. Infelizmente, no final da década de 1980, o Verstehen político e organizacional dos fenômenos públicos perdeu terreno. As disciplinas concorrentes que assumiram a liderança deram maior destaque a perspectivas normativas. Análises e desenhos de políticas inspirados em abordagens que misturam microeconomia, teoria da agência e tipos de dados exclusivamente quantitativos passaram a dominar. Por vezes desprezaram-se os estudos em andamento e pregaram-se receitas gerenciais derivadas de perspectivas ideológicas como a da escolha racional.

O tema dimensão pública foi dominado por dois paradigmas alternativos: perspectivas inspiradas em referências de mercado e de empresas e novas versões de antigas posturas críticas ou mesmo antipositivistas. Embora do ponto de vista ideológico a nova administração pública gerencial e o pósmodernismo pouco tenham em comum, ambos tendem a questionar, quando não a negar, a especificidade das organizações públicas como construtos sociais. O primeiro considera que os princípios de mercado e o tipo de gerenciamento de empresas privadas devem ser usados como parâmetro. O outro considera que o setor público é apenas uma faceta de uma tendência ou desenho muito mais amplo que age através das sociedades, princípios organizados indesejáveis e processos organizadores que oprimem contemporaneamente a humanidade, viabilizando que o capitalismo e a globalização controlem o mundo. Em algumas versões mais extremadas, teorias críticas chegam a defender que as organizações são fenômenos ou artefatos ilusórios e não objeto de conhecimento.

Definida por Max Weber (1922) como um degrau básico no sentido da modernidade e da racionalidade em ato, a burocracia cada vez mais se tornou um bode expiatório e um alvo. É irônico notar que, mais do que sociólogos, economistas como Kenneth Arrow (1974) e Oliver Williamson (1975), para apontar apenas alguns, foram pioneiros em caracterizar empresas como um 
tipo particular de organização. Tais contribuições, os tipos de raciocínio e a tendência pró-mercado que fomentam tiveram forte influência nas análises das organizações públicas no final do século XX. As abordagens da escolha racional e da escolha pública definiram novas fronteiras a respeito de empresas do setor público. A eficiência vem substituindo o legalismo como fonte de legitimidade. Gerenciamento, e não administração, passou a constituir a referência para os regimes políticos no que toca ao setor público. A nova administração pública gerencial, legitimada por instituições internacionais como o Banco Mundial e a OCDE, esteve por trás de boa parte, senão da maior parte, do financiamento público alocado em programas de reforma administrativa do setor público.

\section{O que a teoria-padrão clássica deixou inacabado}

De fato, a sociologia organizacional clássica em parte falhou. Seus representantes mais proeminentes lidaram de forma ambígua com os assuntos ligados à dimensão pública. Na verdade, nem todas as expectativas foram, ou podiam ser, preenchidas. Várias razões endógenas podem explicar o relativo declínio do recurso à sociologia organizacional clássica para o estudo das agências governamentais.

Uma delas pode estar ligada ao termo burocracia.

Seu próprio criador não ajudou ao publicar, na década de 1920, sua teoria da burocracia colocando-a como uma organização formal. Por um lado, inspirou um ambicioso e fecundo programa de pesquisa iniciado no começo da década de 1950 com a contribuição de pioneiros como Robert Merton (1952), Robert Dahl e Charles Lindblom (1953) e Peter Blau (1955). Perdurou por pelo menos 20 anos.

Por outro lado, abriu caminho para uma alocação ambígua do termo burocracia. Três sentidos diferentes se sobrepunham e isso ainda ocorre: um descritivo e conceitual que se podia aplicar a qualquer organização, qualquer que fosse seu estatuto legal; uma forma de nomear qualquer agência controlada pelo Estado; e um sentido pejorativo ligado a uma máquina estatal exagerada, a uma série de exigências e à frustração dos usuários. Apesar dos esforços de autores como Victor Thompson (1961) para evitar confusão e apesar de arcabouços analíticos e conceituais que definiam o modelo e suas funções latentes, elaborados por Robert Merton (1940) ou Michel Crozier (1963), a sociologia das organizações clássica ou padrão estava de certo modo presa na armadilha do estatuto polissêmico da burocracia. 
As motivações orientadoras do programa pessoal de alguns pesquisadores assemelhavam-se ao desapontamento e às preocupações que haviam inspirado Robert Michels (1949) com o que ocorria com os partidos socialistas e os sindicatos nas democracias européias nas décadas iniciais do século XX. O ativismo político trotskista de Philip Selznick na juventude influenciou sua crítica política das instituições do New Deal (Selznick, 1949) e levou Martin Lipset e seus colaboradores (1956) a procurar entender como era possível evitar a lei de ferro da oligarquia e conservar um índice elevado de democracia em sindicatos americanos. O espectro de fontes de inspiração e debate social na base dos estudos organizacionais era bem amplo, indo desde libertários do Sul dos Estados Unidos, como Theodore Lowi, até autores liberais da costa leste, como Graham Allison e Robert Dahl. A crise econômica no início da década de 1930, bem como o gerenciamento dos esforços e das conseqüências da II Guerra Mundial que se lhe seguiu, fomentou o crescimento do governo. Vários modelos de Estado de bem-estar social começaram a se desenvolver dos dois lados do oceano Atlântico.

Em certa medida, o estudo pela sociologia das organizações de instituições governamentais, mas também de partidos políticos e até de empresas, passou a ser visto como excessivamente orientado para pesquisas de campo e para a construção de modelos burocráticos e, portanto, patológicos. Soluções alternativas ou de melhor tipo não eram espontaneamente associadas a este campo de conhecimento. Isto fez com que cedesse espaço para outras abordagens ou disciplinas, consideradas mais afinadas com a modernidade.

Outra razão para as expectativas não satisfeitas pela teoria-padrão está ligada à verificação pouco acurada de postulados.

Isto dá-se tipicamente no tocante às diferenças, se é que existem, entre organizações do setor público e organizações de outros setores. Um aspecto que chama a atenção quanto ao que foi alcançado pelo programa clássico da sociologia das organizações é a relativa incompletude ou ambigüidade das propostas referentes às organizações públicas como fenômeno específico. A título de exemplo, manuais e enciclopédias publicados a partir do fim da década de 1950 (March e Simon, 1958; March, 1965) não contêm artigos nem capítulos dedicados diretamente ao assunto. Isto reflete um fenômeno mais amplo.

Uma opinião largamente partilhada pelos sociólogos organizacionais era que as diferenças existiam de fato. Presumia-se que as empresas privadas eram menos rígidas e mais capazes de responder ao ambiente onde se inseriam. A razão é que têm de sobreviver em mercados competitivos, ao passo que as agências públicas se defrontam com ambientes menos mutantes e mais previsíveis. Postulava-se que as agências públicas são mais eficientes do que as 
empresas privadas quando se almeja desenvolvimento econômico e político. Fred Riggs (1969), por exemplo, defendeu que países em desenvolvimento precisariam que o setor público se tornasse mais proeminente, já que a entidade política estaria "desequilibrada" entre seu forte sistema político e sua fraca esfera de administração pública.

Todavia, as comparações nem sempre se ancoram numa base sólida. Embora alguns casos sejam desconcertantes, os dados mostram de forma consistente que, por exemplo, a presença de um tipo específico e forte de setor administrativo é insuficiente para explicar, mantendo-se todas as demais variáveis constantes, por que se produz ou não desenvolvimento. Diferenças ordinais em vários parâmetros, como propriedades formais ou modos de funcionamento das organizações, eram encaradas como decorrentes de elas serem voltadas para o lucro, sem fins lucrativos ou governamentais. Os estudos de Aston destacaram o tamanho como causa básica (Pugh, 1998). Em outros trabalhos sugeriu-se que a burocratização, medida por níveis de formalização, centralização de autoridade e complexidade na divisão de tarefas, é por vezes bastante elevada em empresas líderes e, por comparação, bastante fraca em agências públicas (Dupuy e Thoenig, 1985). As burocracias estatais não estão por sua própria natureza inclinadas a uma grande rigidez na maneira como funcionam na prática, nem os outros tipos de organização têm por princípio ser menos intrincados. Há bastante espaço na agenda atual para mais pesquisas.

Um aspecto se destaca quanto à interface entre a sociologia das organizações e a dimensão pública. O conhecimento produzido pela disciplina deve muito ao estudo das agências do setor público. Não obstante, a dimensão pública enquanto fenômeno social não tem sido uma preocupação-chave.

Na Europa, e mais ainda nos Estados Unidos, houve contribuições pioneiras de sociólogos sobre agências públicas, muito embora como teste empírico da validade de paradigmas mais amplos. Herbert Simon (1947) dedicou-se a analisar como os responsáveis por parques municipais tomavam decisões a respeito de novos projetos. A doutrina da racionalidade absoluta mostrava-se falaciosa quando se consideravam os comportamentos humanos em ambientes organizados. Philip Selznick (1949) analisou como a Tennessee Valley Authority (Superintendência do Vale do Tennessee), criada pelo presidente Franklin Roosevelt, sofreu processos de institucionalização secundária no nível de suas unidades de base.

Essa tradição trouxe enormes contribuições ao conhecimento sobre organizações em geral e sobre empresas em particular. Agências operantes no setor público foram a base para descobertas inovadoras. Conceitos como cooptação, poder e controle, teorias como culturalismo, funcionalismo e re- 
dundância e sobreposição tiveram grande receptividade. Ao estudar duas agências ligadas ao bem-estar social, Peter Blau (1955) percebeu que a segurança no emprego e a autonomia são condizentes com uma atitude positiva diante da mudança. Michel Crozier (1963) elaborou sua teoria sobre o modo como as normas culturais nacionais permeiam as organizações a partir de monografias a respeito dos correios franceses e da produtora de cigarros, que era de propriedade do Estado. Michael Cohen e James March (1974) desenvolveram o modelo da lata do lixo basicamente a partir de observações sobre como as universidades americanas são geridas. A lista é quase infindável, abrangendo vários dos autores mais destacados da disciplina, desde Amitai Etzioni (1961) e sua descoberta do fenômeno da obediência até Charles Perrow e sua abordagem socioestrutural (1970).

Muito poucos pesquisadores das organizações atacaram o tema da dimensão pública. Peter Blau e Richard Scott (1962), por exemplo, formularam uma tipologia onde diferenciavam as organizações comunitárias (ou públicas) das de negócios, de serviços e de benefício mútuo. Contudo, na maior parte do tempo as organizações públicas eram vistas como ilustrações de um tipo mais genérico de configurações sociais médias chamadas organizações. Qualquer organização, incluindo a empresa, está imersa em dinâmicas e funções de poder como em uma arena política constituída de comportamentos estratégicos (March, 1962). Hoje em dia as perspectivas que recolocam em cena os fenômenos institucionais são amplamente endossadas pelas escolas de negócios e utilizadas na análise de regimes econômicos e do gerenciamento de empresas. Os imperativos de conformidade e legitimidade explicam por que é que formas institucionais análogas se espalham no terreno dos estudos organizacionais. A ironia é que muitos dos estudos pioneiros do institucionalismo sociológico americano (Thoenig, 2003) haviam analisado fenômenos relacionados com o setor público: a difusão de novos padrões de gerenciamento organizacional em cidades (Tolbert e Zucker, 1983), escolas de ensino fundamental (Scott e Meyer, 1994) etc. Em que medida o estatuto público é ou não um diferencial com relação a empresas ou ao status de sem fins lucrativos permanece uma questão em aberto para pesquisa.

\section{Aproveitando os estudos sobre formulação de políticas}

A administração pública como disciplina passou a tratar da questão da burocracia no ponto em que a sociologia das organizações o deixou de lado. Há enorme quantidade de abordagens que a exploraram de vários ângulos (Meier 
e Hill, 2005). De fato, a dimensão organizacional em si permanece essencialmente à margem. Outras abordagens são dominantes.

Em comparação com o conhecimento produzido pela sociologia organizacional, a nova administração pública gerencial, a concepção pós-moderna e a teoria da agência são perspectivas que se baseiam em modelos pobres, quando não em premissas questionáveis. O neoinstitucionalismo trata de reformas administrativas que levam a processos de não-aprendizado em organizações públicas, como se as organizações não fossem autores autônomos e em mudança. As abordagens de rede constituem, em certa medida, uma exceção. Como abordagens, aproveitam-se bastante de avanços notáveis recentes na teoria organizacional aplicada a negócios e à sociologia política.

O que também chama a atenção é que a conexão entre a burocracia e a dimensão pública não foi estabelecida de modo consistente em termos organizacionais.

A distinção entre privado e público, entre gerenciamento visando ao lucro, sem fins lucrativos e governamental tem sido tratada desde que a administração pública despontou como disciplina acadêmica. As décadas de 1970 e de 1980 coincidiram com a publicação de vários artigos clássicos (Rainey, Backoff e Levine, 1976; Lynn, 1981; Rainey, 1989; Yates, 1985). Sugeria-se aí que o gerenciamento público é mais difícil do que o privado; Graham Allison (1980) lista aspectos semelhantes e diferentes. Para além da questão da propriedade, supõe-se que as organizações públicas são diferentes devido à sua exposição à arena política ou à sua dependência de recursos governamentais (Warmsley e Zald, 1973). Barry Bozeman (1987) define a dimensão pública pelo fato de o governo, mais do que fatores de mercado, influenciar a tomada de decisões e os contextos nos quais as organizações operam, independentemente de seu estatuto legal.

Faltam evidências de peso baseadas numa análise organizacional acurada, como indica uma revisão da literatura sobre o assunto (Rainey e Chun, 2005). Ainda predominam discursos normativos, tais como ética e interesse público em países de common law, como intérêt général em Estados que se baseiam no direito romano, ou como prestação de contas. Apesar de a nova administração pública gerencial e de o início dos anos 2000 parecerem considerar o assunto resolvido, o privado sendo em última análise a referência, ainda permanece em vigor a idéia de que a dimensão pública implica um diferencial, como enfatizado por autores como Jonathan Boston (1995).

A influência do institucionalismo, antigo ou novo, e a referência à economia pública continuam fortes. Poucas pesquisas houve que atestassem a validade e a plausibilidade de tais pressupostos. As classificações e critérios permanecem essencialmente descritivos ou institucionais. Pouco esforço foi 
despendido no sentido de construir um arcabouço analítico que de fato dê conta de uma gama mais ampla de características organizacionais, em vez de focar nas propriedades gerenciais.

Alguns autores corretamente apontaram caminhos que os estudos organizacionais deveriam trilhar na exploração da dimensão pública (Schubert, 1960; Goodsell, 1990; Ranson e Stewart, 1989). Por exemplo, o interesse público deveria ser encarado como incluindo tanto interesses subjetivos quanto bens objetivos. As organizações públicas lidam com agendas políticas. O Estado não é um sistema integrado, mas antes se constitui de uma pluralidade de atores mais ou menos autônomos. Os efeitos de políticas são preocupação central. A formulação de políticas é relevante tanto como processo quanto como conteúdo. Discutem-se hipóteses que a teoria organizacional padrão ignorou por anos a fio: a distinção entre uma organização formal e seu ambiente, relações assimétricas e transitivas no âmbito de hierarquias monocêntricas etc. A definição de abordagens heurísticas torna-se um desafio que os estudos organizacionais precisam enfrentar com empenho.

No final da década de 1970 e início da de 1980 vários pesquisadores de administração pública abandonaram a sociologia organizacional stricto sensu e voltaram-se para a sociologia política ou ciência política, muito embora sem perder de foco, antes pelo contrário, as agências governamentais e a dimensão pública enquanto tal. Estudos pioneiros foram desenvolvidos na Europa (Mayntz, 1979; Thoenig e Dupuy, 1979) e nos Estados Unidos (Pressman e Wildavsky, 1973; Bendor, 1985; Chisholm, 1989). Diálogos profícuos ocorreram entre análises de políticas e reflexões organizacionais a partir do estudo de políticas constitutivas, como estudos intergovernamentais e descentralização de assuntos territoriais (Rhodes, 1981; Thoenig, 2006). O acompanhamento de políticas é uma via rica de análise das organizações que recorre a focos ou perspectivas diferenciados.

Uma abordagem proveitosa da dimensão pública a levar em conta no conhecimento sobre organizações presume que as organizações públicas são sistemas sociais guiados por, e que respondem a, duas funções de produção e não apenas uma, caso das empresas e das associações voluntárias (Thoenig, 1985):

v produtos operacionais - esta função está relacionada à eficiência interna, à produção de bens e serviços específicos que podem ser facilmente identificados e enumerados;

V efeitos de mudança societal - esta função de produção carreia a distribuição de efetividade; lida com efeitos sobretudo de médio prazo, indiretos e mais difíceis de quantificar. 


\section{Duas funções de produção}

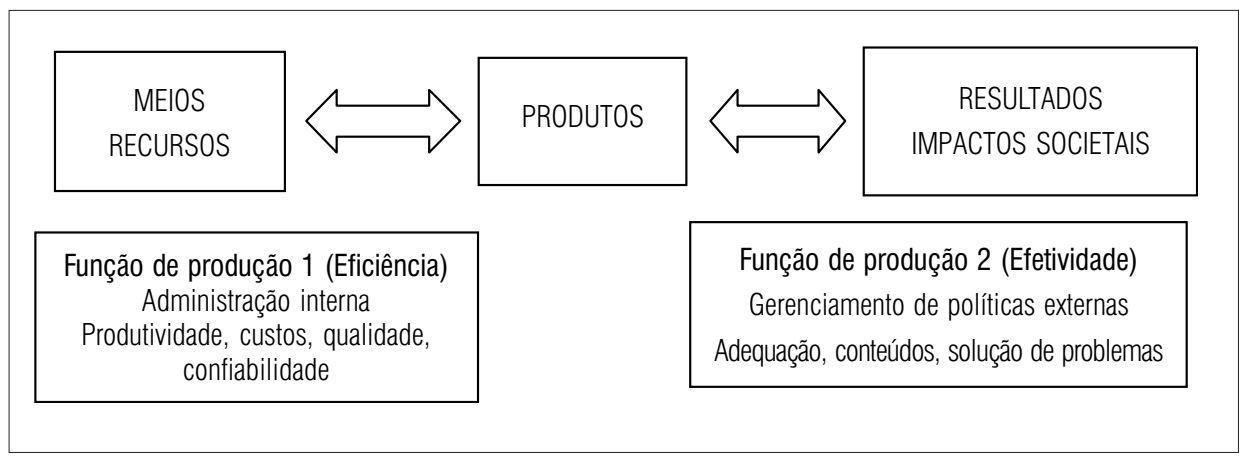

Administração, de um modo geral, refere-se à forma como recursos ou ingressos (por exemplo, dinheiro, pessoal e materiais brutos) se ligam aos produtos visíveis ou acabados (tais como número de carros manufaturados ou volume de petróleo refinado). O objetivo é ou minimizar os recursos empregados para atingir determinado nível de produção ou maximizar a produção para uma determinada quantidade de recursos alocados. Os economistas descrevem esse par como uma função de produção interna. O objetivo a atingir através da hierarquia é eficiência. As ferramentas disponíveis são técnicas e procedimentos como contabilidade, controle de custos, relações humanas, logística etc. O horizonte de tempo é definido convencionalmente e não é tema de debate. Os ciclos orçamentários são de um ano, a produtividade numa fábrica é medida por padrões convencionais etc.

A natureza da eficiência pública é um tema de pesquisa organizacional que permanece em aberto. Produtividade, satisfação dos clientes e custos são critérios, entre outros, a serem levados em consideração. Também foi defendido, bem antes de ser colocado pela nova administração pública gerencial, que a eficiência, como referência normativa, é por demais encarada pelo prisma do sucesso (Landau e Chisholm, 1995). Outras doutrinas de eficiência estão em operação no gerenciamento público, tais como a prevenção de falhas. Neste caso, confiabilidade, ao invés de otimização, é que constitui a base. Redundâncias organizacionais e sobreposições de competência podem implicar uma baixa no desempenho microeconômico de equivalentes substitutos e um aumento do custo estrutural anual. Todavia, quando um acidente grave, catástrofe ou convulsão ocorre, quer meteorológico, quer técnico ou social, o sistema dispõe de folga e de recursos confiáveis suficientes para minimizar as conseqüências.

À exceção de algumas pequenas diferenças de ordem legal (estatuto dos funcionários, regras de posse e de contabilidade), as agências públicas defron- 
tam-se com contextos administrativos semelhantes aos das empresas privadas que agem no mercado. O gerenciamento interno é bem semelhante em ambos os universos. Não obstante, e isto é que faz toda a diferença, a administração organizacional do setor público deve levar em conta uma segunda função de produção, o que as organizações privadas não precisam. Esta função é chamada efetividade. Não é interna à instituição, mas sim externa. Está inserida num tecido social de algum gênero. É, portanto, mais complexo administrar uma organização pública do que uma privada.

A efetividade refere-se ao modo como resultados específicos ou produtos, bens e serviços acabados estão ligados causalmente aos efeitos das políticas e aos impactos societais que se presume deveriam ter. Estes efeitos e impactos têm uma natureza especial, quando comparados com resultados e produtos. Não há um prazo convencional que defina quando tais avaliações devam ser feitas, como e segundo quais indicadores. A organização pública não detém a priori o monopólio de sua definição. Agrupamentos mais ou menos voláteis expressam opiniões não convergentes a respeito, selecionam aqueles que para eles fazem sentido, julgam, avaliam mais ou menos espontaneamente que impactos societais específicos constituem um sucesso ou um fracasso e se podem ser atribuídos a uma política específica endossada por uma instituição pública específica.

Para avaliar o grau de presença da dimensão pública é menos importante considerar se é ou não uma organização estatal, ou formalmente controlada pelo Estado, do que verificar se enfrenta restrições na definição de seus critérios de sucesso e de suas metas básicas. Num mesmo país pode haver diferenças significativas entre agências públicas. Algumas operam como se fossem empresas privadas, definindo suas próprias metas e critérios de eficiência, sem ter que prestar contas de qualquer função de efetividade. Outras têm de facto de prestar contas de ambas as funções de produção. Presume-se que devam ser de certa forma eficientes sem deixar de ser efetivas. Como é que se alcança o equilíbrio entre as duas funções de produção, e com que conseqüências, é tema que requer mais pesquisas.

\section{Um arcabouço analítico}

Enquanto conceito, a dimensão pública caracteriza-se por quatro aspectos básicos:

$\checkmark$ domínio de impactos societais;

$\checkmark$ mandatos para políticas legitimados por autoridade governamental; 
V indicadores de sucesso e fracasso múltiplos e divergentes;

v ausência de auto-avaliação espontânea.

Uma organização pública gerencia uma política cujos objetivos últimos são definidos e avaliados por terceiros: alguma autoridade governamental, quando não um grupo heterogêneo de interessados, públicos e privados.

As organizações públicas por si só não legitimam as metas ou impactos das políticas que manejam. Quem o faz são terceiros, normalmente autoridades políticas que governam a área e têm legitimidade para agir. Alocam fundos, indicam pessoal, financiam a aquisição de equipamentos etc. Espera-se induzir dois tipos de efeitos. Evitar ou minorar os aspectos negativos, aqueles que, de outra forma, causariam fraturas na sociedade: crime, pobreza, proteção contra incêndios, poluição de ar e água etc. Aspectos positivos devem ser gerados, deve haver resultados que induzam melhorias ou satisfaçam aspirações que, de outra forma, se nada for feito pelo governo e pelo Estado, não serão providas espontaneamente pela sociedade civil: desenvolvimento cultural e acesso à produção artística, desenvolvimento econômico local, acesso aos mercados de trabalho etc. Políticas públicas não são apenas políticas de organizações públicas. Entidades políticas desenham, e políticas governamentais legitimam, um conjunto de normas e ações coletivas sobre mudanças societais às quais se espera que os empreendimentos públicos se ajustem. Razões exógenas e realizações são a moldura da efetividade. Constituem a essência de um empreendimento público.

As evidências mostram que o poder das autoridades políticas varia. Por vezes podem não parecer proativas, mas seus não-atos são atos que têm importância e conseqüências. Na maior parte do tempo, os impactos almejados não são definidos em detalhe e a priori. A racionalidade política ou os ciclos eleitorais podem levar autoridades governamentais a evitar um compromisso com metas quantitativas e de longo prazo. O Executivo e o Legislativo preocupam-se mais com os impactos simbólicos e com o endosso imediato da opinião pública do que com as conseqüências efetivas a longo prazo. As agências podem até ser deixadas por conta própria, modificando de forma tecnocrática suas técnicas e rotinas e interpretando as metas a serem atingidas. Em determinadas circunstâncias, motivações de ordem mais cínica podem estar em operação. Autoridades governamentais promulgam novas leis e anunciam novas políticas tendo plena noção das dificuldades de implementá-las na prática. Apostam em conseguir apoio da opinião pública, e não em efeitos duradouros no dia-a-dia. A mensagem latente soa como "não se aflija, nós estamos aten- 
tos". Todavia, em última análise, a prestação de contas e a tomada de iniciativas permanecem atributos da arena política.

As organizações públicas desempenham um papel societal que vai bem além de sua função técnica de provedoras de bens e serviços. Moldam a sociedade, a entidade política e a ecologia, constroem e influenciam deliberadamente seus próprios ambientes. O reforço de sua legitimidade para agir e produzir impactos na sociedade é uma das principais incertezas com que se defrontam.

Uma agência pública pode, por exemplo, estar encarregada da manutenção de certo tipo de estradas numa determinada área geográfica. Para fazêlo, ela própria pode prover todos os produtos concernentes ao seu mandato. Pode também subcontratar a produção a fornecedores privados. De qualquer maneira a raison d'être de sua função de produção interna ou eficiência não é aumentar sua participação no mercado de manutenção de estradas ou apresentar um lucro que maximize a satisfação de seus proprietários ou diretores. O que de fato importa em última análise é que a segurança no tráfego não piore, que o transporte flua melhor, que os políticos que estão à frente dessa jurisdição pública não sejam detratados pelos eleitores locais.

De qualquer forma, descrever esses impactos societais é algo que está longe de ser óbvio. As organizações públicas defrontam-se com um universo que prima pela ambigüidade. Nem sempre é fácil avaliar até que ponto os impactos ou resultados são conseqüência direta de causas tais como os produtos oferecidos pela agência. Para além disso, a racionalidade política, que implica a oferta aos formuladores de políticas da possibilidade de não serem encarados como responsáveis por suas decisões passadas, quaisquer que tenham sido seus impactos, faz com que o ambiente das organizações públicas seja bastante volátil e indeterminado. Introduzir as agências públicas no tecido social e político é uma forma de induzir efetividade. Em certa medida, o mapeamento reverso e a reinterpretação das regras são práticas bastante comuns ao nível dos burocratas que trabalham diretamente com o público (Elmore, 1979).

A dimensão pública significa que as agências se confrontam com duas fontes de conhecimento.

Uma delas está ligada à estrutura de sua organização formal. As organizações de um modo geral são construtos sociais que almejam obter alguma confiabilidade coletiva para atores de risco, como indivíduos ou pequenos grupos. Como tornar diferentes lógicas de ação compatíveis de forma a produzir um determinado tipo de bens e serviços é talvez o desafio acadêmico mais fundamental com que nos defrontamos desde há um bom tempo. Propriedades fundamentais de uma organização, como centralização de autoridade, relações assimétricas e lineares, especialização de tarefas e atribuições, regras de decisão tanto procedimentais quanto substantivas, configuram uma estru- 
tura de conhecimento, uma teoria (Thoenig, 1998). Antecipam as conseqüências a serem produzidas. Definem o que acontecerá quando certas ações são produzidas, quando tais e tais intervenções governamentais ocorrem em determinada área de certa maneira. O conhecimento é perfeito quando não ocorrem falhas, quando as soluções formais para as operações a serem levadas a cabo estão sempre corretas. Organizações fornecem certeza e confiabilidade.

Outra fonte de conhecimento deriva das próprias políticas. Políticas também são teorias, mas de uma natureza diferente daquela das organizações. Qualquer política mistura algumas premissas normativas com outras factuais. A pena de morte é uma política judicial. A sua raison d'être pode ser formulada a partir de duas premissas fundamentalmente diferentes. Uma é de ordem moral ou ideológica. A punição encontra legitimidade como dever social ou como vingança ética. Os que mataram têm de pagar por seu crime com sua própria morte. Este tipo de valor está estabelecido ou é partilhado a priori. Não são valores testáveis nem sujeitos a comprovação. Outro tipo de premissa que dá legitimidade à pena de morte é de ordem factual. Evitação seria um exemplo típico. Espera-se que os acontecimentos futuros sejam diferentes dos do passado. Assassinos potenciais passariam a ter medo de cometer assassinato. As conseqüências podem ser mapeadas, testadas do ponto de vista empírico e posteriormente avaliadas.

Premissas baseadas em fatos são hipóteses (Landau, 1977). Uma determinada política propõe um conjunto de ações e não-ações para modificar algum contexto ou tipo de procedimento existente. É intencional na medida em que expressa a vontade de um formulador de políticas. É concebida para alcançar determinadas metas ou resultados futuros por meio da produção atual de determinados produtos. As políticas estão, portanto, descrevendo ou postulando, de forma mais ou menos implícita, três componentes: uma situação almejada, uma situação presente suposta e um conjunto de meios para modificar a situação presente no futuro. Definem conexões "se-então". Supõe-se que as políticas controlem e orientem os cursos futuros da ação num universo que é incerto e arriscado. A função de suas demandas empíricas é eliminar o erro.

Os fatos sugerem que erros são comuns e que fenômenos disfuncionais são recorrentes.

$\mathrm{O}$ primeiro está ligado a erros da teoria na qual a política se baseia. $\mathrm{O}$ outro pode derivar de pressupostos equivocados sobre efetividade no tocante a fenômenos sociais, econômicos e ecológicos. Pressupostos errados são construídos a respeito da situação concreta atual e, portanto, sobre a probabilidade de gerar a situação desejada no futuro. Um exemplo é o da pena de morte, que não dissuade assassinos. Os autores de políticas ignoram a realidade sobre a qual intervêm e têm representações equivocadas a respeito das 
condutas a serem modificadas e das dinâmicas que é preciso mobilizar para esse fim. Um uso mais acurado do conhecimento científico relacionado com a área das políticas em pauta - criminologia, por exemplo - pode fornecer instrumentos para uma maior efetividade.

Um segundo aspecto deriva de disfunções na eficiência. O gerenciamento interno pode ser fraco, as estruturas formais inadequadas. A implementação é um elemento-chave. As autoridades governamentais apóiam-se totalmente nas organizações no tocante à implementação. Os dados evidenciam de forma consistente que tal transferência está longe de ser tranqüila. Permanece uma fonte de riscos e perdas. Estudos sobre políticas chegam a sugerir que dois terços das falhas se devem ao que ocorre durante a implementação ou fase de administração. A implementação, quando efetivada pelas organizações, está sujeita à rotinização e à influência de preconceitos. A organização formal como fonte de erros aumenta geometricamente seu número e intensidade. Um exemplo são os comportamentos discricionários dos funcionários que lidam diretamente com o público, os quais, quando não controlados de perto por seus supervisores, podem levar certas medidas políticas ao fracasso. Determinada lei existe, mas não é completamente cumprida. Isto pode derivar tanto de erros nas próprias políticas como simplesmente de falhas administrativas. A organização específica à qual as autoridades governamentais delegam a implementação de determinada política não a assume nem toma a si a responsabilidade de executá-la.

As organizações públicas corrigem seus erros? Gerenciar simultaneamente duas funções de produção faz com que essas organizações sejam um contexto difícil de lidar. Disfunções internas podem gerar disfunções externas.

As regras e estruturas formais são voltadas para a solução antecipada de problemas e espera-se que as diversas unidades da agência se ajustem a isso. Ao mesmo tempo, espera-se que a organização produza e lide com informações sobre seu ambiente e sobre o impacto de sua estrutura de conhecimento. Informação significa surpresa, anomalia, indicação de que algo está errado a respeito do curso da ação e da própria estrutura de conhecimento. Os dados sugerem que a dimensão pública conduz a uma evitação do uso dos erros como incentivo à correção da estrutura de conhecimento.

Como várias organizações privadas e organizações sem fins lucrativos, as agências públicas freqüentemente demonstram um nível elevado de conhecimento. Os problemas decorrem do fato de que quanto mais a organização detém conhecimento, menos informação ela tem, menos identifica e lida com os erros como falta de conhecimento adequado e como fonte de informação. Erros tornam-se pecados a serem evitados, um estado patológico que deve ser escondido, ao invés de oportunidades de aprendizado, um indicador que aju- 
dará a definir e entender as tomadas de ação futuras. Quando ocorrem erros, as pessoas são freqüentemente punidas, ao passo que os erros em si não são espontaneamente corrigidos.

Diferentemente de outros tipos de organização, e por causa de sua função de produção de efetividade, as agências públicas enfrentam outro obstáculo no processo de correção de erros e uso de informações. Como referido antes, na maioria dos casos, os indicadores de impactos externos são vagos e carregados ideologicamente, os objetivos duvidosos, os horizontes temporais controversos e instáveis, os eixos causais entre políticas específicas e determinado conjunto de resultados não lineares e difíceis de serem estabelecidos. Falta até uma autoconsciência básica.

A avaliação de políticas não é promovida de modo espontâneo nem é algo óbvio. A idéia de gerenciar uma avaliação de efetividade é meta difícil de atingir, uma utopia (Thoenig, 2000). Avaliação e organização são de certa forma contraditórias. As agências públicas enquanto organizações não avaliam suas próprias atividades na maior parte do tempo (Wildavsky, 1979). Não corrigem erros e aspectos inesperados produzidos tanto pela teoria da ação envolta em sua estrutura organizacional quanto pela teoria societal implícita nas políticas que têm por tarefa implementar. Ao invés, confiam na sua capacidade para reconhecer necessidades sociais que devem ser supridas e as formas efetivas de fazê-lo. Eficiência e efetividade são relevantes na medida em que seus critérios e resultados se coadunem com a estrutura de conhecimento. Caso contrário, são encaradas como despidas de sentido. As organizações públicas preferem descartá-las como propulsoras da ação. As políticas essencialmente reproduzem-se a si próprias.

\section{De organização a organizante e organizado}

Os arcabouços teóricos e conceituais não são objetivos em si. Fornecem meios. São úteis como ferramentas para explicar determinados problemas e são obstáculo à compreensão de outros. A dimensão pública como definida neste artigo oferece uma perspectiva heurística para analisar a ação pública e a forma pela qual as organizações públicas para ela contribuem.

Os estudos de organizações públicas têm muito a ganhar em manter proximidade com as análises de políticas. Aumentam o Verstehen do que as autoridades governamentais fazem e dos assuntos públicos abordados. Trazer de volta a formulação de políticas e as entidades políticas permite à pesquisa acadêmica lidar com conteúdo, em vez de se restringir aos processos. Também oferece uma visão mais ampla. Rotinas cotidianas, estruturas formais e fun- 
cionamentos internos das agências são parte de uma arena mais global de ação, a formulação de políticas.

Uma contribuição fundamental ao estudo da dimensão pública que a perspectiva baseada na ação provê é de ordem empírica.

Na maioria das áreas, os problemas são tratados por mais de uma agência formal. Em outros termos, o que acontece num setor é conseqüência do que várias políticas e burocracias públicas empreendem, intencionalmente ou não. O desemprego é conseqüência de vários atos e não-atos governamentais, desde a localização de moradias para pessoas de baixa renda até incentivos fiscais e programas de treinamento. Vários setores políticos e agências têm efeitos combinados sobre sua taxa e sua estrutura. Em termos mais gerais, uma política específica induz efeitos e impactos não apenas sobre o problema particular para o qual foi concebida, mas também sobre outros problemas e sobre o modo como outras políticas operam e geram impactos na sociedade. Na verdade, é bastante incomum que uma organização formal específica detenha o monopólio e controle exclusivo sobre uma atribuição política.

O que se percebe repetidamente é que as agências públicas não atuam de modo autárquico. Suas ações e não-ações não são a única coisa que pesa na solução de determinado item da agenda governamental. Várias organizações com outro tipo de estatuto legal — organizações voluntárias, empresas privadas, instituições filantrópicas etc. — intervêm, formal ou informalmente, como subcontratadas, implementadoras de políticas, solucionadoras de problemas etc. A ciência política define esses conjuntos através de metáforas ou expressões como arenas de políticas ou comunidades. Desenvolvimento econômico local, bem-estar social, saúde, crime e leis, transporte público são apenas algumas das áreas políticas nas quais se pode perceber essas coalizões em operação. A lição a ser aprendida é que os temas públicos e o modo como são tratados não devem ser vistos sob uma perspectiva centrada no Estado. Políticas públicas lidam com problemas coletivos, que envolvem várias instituições e organizações. As agências públicas e o Estado são apenas alguns entre vários atores, por vezes mais poderosos e relevantes do que os outros, por vezes menos.

As observações precedentes têm conseqüências significativas em termos dos estudos organizacionais. Uma revisão das publicações a respeito (Thoenig, 1997) classifica as organizações públicas de acordo com o grau em que seu funcionamento interno é impermeável ou sensível à dinâmica e aos fatores externos. Arrolam-se quatro tipos:

v um tipo orientado para dentro - o funcionamento organizacional fecha-se ao ambiente que o envolve; 
v um tipo sensível ao ambiente - o funcionamento leva em conta os riscos, grupos e problemas externos, através da demonstração de sensibilidade às capacidades locais ou da institucionalização de processos de cooptação, realizados formal ou informalmente;

v um tipo orientado para o exterior - porque a organização é altamente dependente de forças externas, sejam elas de ordem profissional ou de recursos como os informacionais, a dinâmica centrífuga tem maior peso do que sua autoridade hierárquica;

> um tipo de funcionamento em esquema interorganizacional — a organização formal não fornece a estrutura para sua própria integração, sendo regulada por algum tipo de rede ou sistema de ação coletiva mais amplo e bastante estável do qual é parte.

As organizações formais não são a única forma de obter determinados resultados. Outras configurações e processos sociais tais como organizantes e organizados fornecem soluções alternativas. Tornar diferentes lógicas de ação compatíveis de forma duradoura e sem maiores problemas é algo que pode ser obtido de outras formas além do recurso à hierarquia do princípio de autoridade. Ajustes políticos e cooperação entre agências e operadores públicos diferentes, desde que não antagônicos do ponto de vista retórico, podem ser até algo mais fácil de induzir quando não se recorre às estruturas formais de coordenação que os atravessam. Combinar análise de políticas e análise organizacional leva a perceber e interpretar outras formas de cooperação social voluntária: cooptação informal, regulamentação cruzada, redundância, ação coletiva, redes etc. Pesquisadores de organizações públicas estavam, de certo modo, à frente das empresas privadas. É no final da década de 1980 que estas últimas passaram a dar atenção a mecanismos análogos, envolvendo operadores atuantes nos mercados econômicos, como joint ventures, alianças estratégicas etc.

Esse programa de pesquisa começou no final da década de 1970. Dois processos sociais básicos foram trazidos à tona pelas ciências sociais: organizante e organizado.

Organizante refere-se ao modo pelo qual atores distintos ligados por algum tipo de interdependência constroem um padrão, permitindo comportamentos recorrentes e confiabilidade de ação. Que esquemas normativos e processos comportamentais são estabelecidos e difundidos? De que forma e por que são a tomada de ação e a divisão do trabalho processos quase negociados (Thoenig e Dupuy, 1979)?

Organizado refere-se a como as configurações sociais crescem e evoluem de uma maneira que não é coordenada por um centro, mas antes por um 
núcleo multicêntrico. Como é que normas sociais partilhadas — regras sobre regras ou regras secundárias (Reynaud, 1989) — emergem e são construídas, de forma a estruturar modos adequados de conduta e a desenhar regras de operação - ou regras primárias? Que mecanismos integrativos estão em ação, como doutrinação, dominação, regulação ou oportunismo derivado de interesse próprio? De que modo se alcança a integração social quando não há limites claros definindo as fronteiras, as margens de pertencimento, quando as relações entre as diversas partes não são transitivas e quando a assimetria entre níveis é muito baixa? Quais são as capacidades em termos de desempenho de tais ou tais tipos de esquemas organizados?

Esses temas foram ignorados por muito tempo pelos estudos organizacionais. Voltados essencialmente para as organizações como meios formais de cooperação humana, assumiram que para explicar fenômenos sociais dentro de uma agência pública bastava observar o que ocorria no âmbito legal ou formal, em alguns casos acrescentando os usuários como fonte de observação. Alguns poucos trabalhos pioneiros haviam sugerido que ignorar o cenário mais amplo poderia atrapalhar o avanço do conhecimento nos estudos organizacionais e dedicavam-se a identificar construtos sociais, como a cooptação na base das elites locais e a institucionalização (Selznick, 1949) ou a troca de favores entre os escritórios das agências e os políticos locais (Crozier e Thoenig, 1976). O apoio de, e o conflito com, lobbies da sociedade civil e ambientes sociais eram encarados como vetores organizacionais das agências do setor público. Policiais, assistentes sociais, fiscais de impostos, para referir apenas alguns, cumprem uma missão pública, garantem o cumprimento de regras específicas e de procedimentos codificados. Seu sucesso ou fracasso depende, não obstante, em medida às vezes bastante significativa, de acesso a, e suporte de, recursos locais providos por terceiros: para obter informações privilegiadas, identificar usuários, conseguir ajuda de informantes confiáveis e aliados etc. Apesar destas descobertas instigantes, de modo talvez surpreendente, os estudos sobre organizações públicas não se conectaram de fato a outras concepções de pesquisa; isto até que políticas e sistemas de ação quase-organizados dessem lugar a um novo tipo de abordagem.

Um corolário dessa ruptura notável é de ordem metodológica. Se é verdade que organizações formalmente autônomas podem depender de outras quando lidam com determinado problema ou implementam determinada política, então isto implica que é determinado problema ou política que estrutura um tipo de estrutura organizada e atividade organizante num conjunto de atores, que gera este conjunto e provê a interdependência requerida para a cooperação. Em outros termos, o conteúdo e o contexto de um problema ou de uma política desenham tipos interorganizacionais de configurações sociais. 
Geralmente de forma implícita, podem, todavia, ter um caráter bastante estabelecido, duradouro etc. Uma agência pública pode, pois, ser parte de vários destes cenários interorganizacionais. Requisitos de ação e ordenamento são complexos demais para que com eles se lide de modo organizado, são no mínimo de maior complexidade do que havia pensado a sociologia clássica da organização inspirada no modelo formal de Max Weber. A burocratização lida apenas com um dos lados da história do setor público e da ação pública.

Ainda se precisa de pesquisas adicionais para entender de forma sistemática uma ampla gama de questões. Talvez valha a pena mencionar três delas.

、 Tipos específicos de configurações organizacionais estão diretamente vinculados a instrumentais específicos de políticas como gênero de financiamento, regras ou desenhos de instituições?

Dispomos de várias tipologias que classificam as políticas segundo determinados critérios, como o grau de coerção que exercem sobre os grupos e os indivíduos cujas práticas e estatuto visam modificar (Salisbury, 1968) ou como o ferramental a que as autoridades governamentais recorrem para elaborá-las (Hood, 1983). Seria conveniente poder contar com trabalhos mais sistemáticos e de caráter comparativo que avaliassem se tal covariação ocorre. Projetos de pesquisa pioneiros levados a cabo, por exemplo, por Renate Mayntz e seus colaboradores sobre processos de implementação na Alemanha abriram caminho para isso (Marin e Mayntz, 1991).

、 Quais são as conseqüências da dissociação entre poder e autoridade? É verdade que as dinâmicas de negociação horizontal facilitam a eficiência e a efetividade bem mais do que a autoridade hierárquica? É fato que processos de controle e comando implicam dificuldades dramáticas na imposição de seus esquemas a periferias que estão longe de ser passivas, como parece ser o caso, por exemplo, de temas e setores associados à descentralização territorial (Thoenig, 2005) ou ao governo urbano (Le Galès, 1998)? Caso afirmativo, que implicações isso tem em termos de valores organizacionais, como a busca do interesse geral, e das competências profissionais no âmbito das agências públicas? Será que a burocratização administrativa e a codificação estreita das ações constituem meros obstáculos patológicos ou serão contrapartidas necessárias para que a democracia participativa funcione?

\ As cognições organizacionais são importantes?

Os sociólogos organizacionais clássicos ignoraram-nas. Pesquisas orientadas para a avaliação de políticas deram-lhes mais atenção. Os interessados exprimem juízos normativos e mobilizam preconceitos quando consideram 
que uma política falha ou é bem-sucedida. As agências estatais se protegem de forças centrífugas e demandas particulares que emanam da sociedade civil e da entidade política através da construção de barreiras, como normas profissionais e referências de identidade moral tais como o interesse geral. A natureza deste gênero de fenômeno é claramente de ordem cognitiva. Tais critérios devem ser analisados em ação e não apenas como um aglomerado de discursos ou um cenário dos assim chamados mapas cognitivos. Cognições partilhadas ou linguagens comuns para a ação não são nem argumentações nem artefatos retóricos. Tampouco podem ser restritas a expressões locais de fenômenos exógenos e globais, como ideologias de classe ou culturas profissionais. Elas induzem conseqüências empíricas. Além disso, são geradas por cenários organizados. Houve alguns progressos na análise de processos de cognição em empresas (Michaud e Thoenig, 2003). Os estudos sobre organizações públicas ainda têm um bom caminho a percorrer no tocante a este assunto.

A relevância da dimensão pública deveria ser testada, por si mesma e como ferramenta analítica. Vale a pena considerar seu valor agregado na medida em que contribua para o avanço da teoria geral das organizações, organizantes e organizados, mas também para a compreensão da administração pública e das políticas em sociedades multiníveis.

\section{Referências bibliográficas}

ALLISON, G. Public and private management: are they fundamentally alike in all unimportant respects? In: PUBLIC MANAGEMENT RESEARCH CONFERENCE, 1979. Proceedings... Washington, DC: Office of Personnel Management, 1980. (Document 12753-1).

ARROW, K. The limits of organization. New York: Norton, 1974.

BENDOR, J. B. Parallel systems: redundancy in government. Berkeley: University of California Press, 1985.

BLAU, P. The dynamics of bureaucracy: a study of interpersonal relations in two government agencies. Chicago: University of Chicago Press, 1955.

; SCOTT, W. R. Formal organizations. Novato: Chandler \& Sharp, 1962.

BOSTON, J. Inherently governmental functions and the limits to contracting out. In:

(Ed.). The state under contract. Wellington: Bridget Williams Books, 1995. 
BOZEMAN, B. All organizations are public: bridging public and private organizations. San Francisco: Jossey-Bass, 1987.

CHISHOLM, D. Coordination without hierarchy: informal structures in multiorganizational systems. Berkeley: University of California Press, 1989.

COHEN, M.; March, J. G. Leadership and ambiguity: the American college president. New York: McGraw-Hill, 1974.

CROZIER, M. The bureaucratic phenomenon. Chicago: University of Chicago Press, 1963.

; THOENIG, J.-C. The regulation of complex organized systems. Administrative Science Quarterly, v. 21, p. 547-570, Dec. 1976.

DUPUY, F.; THOENIG, J.-C. L'administration en miettes. Paris: Fayard, 1985.

ELMORE, R. F. Backward mapping: implementation research and policy decisions. Political Science Quarterly, v. 94, n. 4, p. 601-616, 1979.

ETZIONI, A. A comparative analysis of complex organizations. New York: Free Press, 1961.

GOODSELL, C. T. Public administration and the public interest. In: WAMSLEY, G. L. et al. (Eds.). Refounding public administration. London: Sage, 1990.

HOOD, C. The tools of government. London: Macmillan, 1983.

HOROWITZ, I. L. The decomposition of sociology. Oxford: Oxford University Press, 1993.

LANDAU, M. Redundancy, rationality, and the problem of duplication and overlap. Public Administration Review, v. 29, n. 4, p. 346-358, 1969.

. The proper domain of policy analysis. American Journal of Political Science, v. 21, n. 2, p. 423-427, 1977.

; CHISHOLM, D. The arrogance of optimism: notes on the failure-avoidance management. Journal of Contingencies and Crisis Management, v. 3, n. 2, p. 67-80, 1995.

LE GALÈS, P. Government and governance of regions: structural weaknesses and new mobilizations. In: 1998. p. 239-265. ; LEQUESNE, C. (Eds.). Regions in Europe. London: Routledge,

LIPSET, S. M.; TROW, M. A.; COLEMAN, J. S. Union democracy. Glencoe: Free Press, 1956.

LYNN, L. Managing the public's business. New York: Basic Books, 1981.

MARCH, J. G. The business firm as a political coalition. Journal of Politics, v. 24, n. 4, p. $662-678,1962$.

(Ed.). Handbook of organizations. Chicago: Rand McNally, 1965. 
; SIMON, H. A. Organizations. New York: Wiley, 1958.

MARIN, B.; MAYNTZ, R. Policy networks: empirical evidence and theoretical considerations. Boulder: Westview, 1991.

MAYNTZ, R. Public bureaucracies and policy implementation. International Social Science Journal, v. 31, p. 633-645, 1979.

MEIER, K. J.; HILL, G. C. Bureaucracy in the twenty-first century. In: FERLIE, E.; LYNN JR., E.; POLLITT, C. (Eds.). The Oxford handbook of public management. Oxford: Oxford University Press, 2005. p. 51-71.

MERTON, R. K. Bureaucratic structure and personality. Social Forces, v. 18, p. 560-568, 1940.

Press, 1952.

; GRAY, A. P.; HOCKEY, B.; SELVIN, H. H. A reader in bureaucracy. Glencoe: Free

MICHAUD, C.; THOENIG, J.-C. Making strategy and organization compatible. London: Palgrave Macmillan, 2003.

MICHELS, R. Political parties. Glencoe: Free Press, 1949.

PERROW, C. Organizational analysis: a sociological view. London: Tavistock, 1970.

PRESSMAN, J.; WILDAVSKY, A. Implementation. Berkeley: University of California Press, 1973.

PUGH, D. S. The Aston programme. London: Ashgate, 1998.

RAINEY, H. G. Public management: recent research on the political context and managerial roles, structures and behaviors. Journal of Management, v. 15, n. 2, p. 229-250, 1989.

; BACKOFF, R. W.; LEVINE, C. N. Comparing public and private organizations. Public Administration Review, v. 36, n. 3, p. 233-244, 1976.

; CHUN, Y. H. Public and private management compared. In: FERLIE, E.; LYNN JR., L. E.; POLLITT, C. (Eds.). The Oxford handbook of public management. Oxford: Oxford University Press, 2005. p. 72-102.

RANSON, S.; STEWART, J. Management in the public domain. Political Studies, v. 37, n. 1, p. 5-24, 1989.

REYNAUD, J. D. Les règles du jeu: l'action collective et la régulation sociale. Paris: A. Colin, 1989.

RHODES, R. A. W. Control and power in central-local relations. Aldershot: Gower, 1981.

Rap Rio de Janeiro Edição Especial Comemorativa 9-36, 1967-2007 
RIGGS, F. Bureaucratic politics in comparative perspective. Journal of Comparative Administration, v. 1, n. 1, p. 5-38, 1969.

SALISBURY, R. H. The analysis of public policy: a search for theories and roles. In: RANNEY, A. (Ed.). Political science and public policy. Chicago: Markham, 1968. p. 151-178.

SCHUBERT, G. The public interest: a critique of the theory of a political concept. Glencoe: Free Press, 1960.

SELZNICK, P. TVA and the grass roots. Berkeley: University of California Press, 1949.

SCOTT, W. R.; MEYER, J. W. Environmental linkage and organizational complexity: public and private schools. In: SCOTT, W. R.; MEYER, J. W. et al. (Eds.). Institutional environments and organizations: structural complexity and individualism. Thousand Oaks: Sage, 1994. p. 137-151.

SIMON, H. A. Administrative behavior: a study of decision-making processes in administrative organizations. New York: Free Press, 1947.

THOENIG, J.-C. Lanalyse des politiques publiques. In: GRAWITZ, M.; LECA, J. ; THOENIG, J.-C. (Eds.). Traité de science politique. Paris: Presses Universitaires de France, 1985. v. 4, p. 1-60.

Public Sector Organizations. In: SORGE, A.; WARNER, M. (Eds.). Handbook of organizational behavior. London: Thomson Business Press, 1997. v. 5, p. 421-432.

. How far is a sociology of organizations still needed? Organization Studies, v. 19, n. 2, p. 307-320, 1998.

Evaluation as usable knowledge for public management reforms. Evaluation, v. 10, n. 2, p. 217-232, 2000.

Institutional theories and public institutions: traditions and appropriateness. In: PETERS, G.; PIERRE, J. (Eds.). Handbook of public administration. London: Sage, 2003. p. $127-148$.

. Territorial administration and political control: decentralization in France. Public Administration, v. 83, n. 3, p. 685-708, 2005.

. Territorial politics. In: RHODES, R. et al. (Eds.). Handbook of political institutions. Oxford: Oxford University Press, 2006.

; DUPUY, F. Public transportation policy making in France as an implementation problem. Policy Science, v. 11, n. 1, p. 1-18, 1979.

THOMPSON, V. A. Modern organization. New York: Knopf, 1961. 
TOLBERT, P. S.; ZUCKER, L. G. Institutional sources of change in the formal structure of organizations: the diffusion of civil service reforms (1880-1935). Administrative Science Quarterly, v. 28, n. 1, p. 22-39, 1983.

WAMSLEY, G. L.; ZALD, M. N. The political economy of public organizations. Lexington: Heath, 1979.

WEBER, M. Wirtschaft und Gesellschaft. Tübingen: Mohr, 1922.

WILDAVSKY, A. Speaking truth to power: the art and craft of policy analysis. Boston: Little Brown, 1979.

WILLIAMSON, O. E. Markets and hierarchies: analysis and antitrust implications. New York: Macmillan, 1975.

YATES, D. The politics of management. San Francisco: Jossey-Bass, 1985. 